\title{
$\underline{\mathbf{P}-31}$
}

\section{Aporphine and Bisbenzylisoquinoline Alkaloids from Roots of Alseodaphne Corneri Kosterm (Lauraceae)}

\author{
Siti Nor Fadzilah Mohammad ${ }^{1, *}$, Kartini Ahmad ${ }^{1}$, Khalijah Awang ${ }^{2}$ and Mohd Azlan Nafiah ${ }^{1}$ \\ ${ }^{1}$ Department of Chemistry, Faculty of Science and Mathematics, University of Pendidikan Sultan Idris, 35900 Tanjung \\ Malim, Perak, Malaysia; ${ }^{2}$ Centre for Natural Products and Drug Discovery, Block D, Department of Chemistry, Faculty \\ of Science, University of Malaya, 50603 Kuala Lumpur, Malaysia; E-mail: zilatwinkle2@gmail.com
}

In Malaysia, there about 15 genera and 212 species of Lauraceae family and one of the species that reported contained various aporphine and bisbenzylisoquinoline types alkaloids is Alseodaphne corneri Kosterm. The plant of this family growth in moderate size in Singapore, Malaysia, Jawa, Sumatra and Borneo. The phytochemical study of the roots of Alseodaphne corneri (Lauraceae) had been carried out. Chromatographic separation of the alkaloid extract led to the isolation of four isoquinoline alkaloids namely laetanine (1), boldine (2), $O$-methyllimacusine (3) and stephasubine (4). The isolation and purification of the alkaloids were achieved using column chromatography (CC) and preparative thin layer chromatography (PTLC). The structural elucidation was performed by spectral methods mainly UV, IR, NMR including $1 \mathrm{D}-\mathrm{NMR}\left({ }^{1} \mathrm{H}\right.$ and $\left.{ }^{13} \mathrm{C}\right)$ and 2D-NMR (COSY, HMQC and HMBC).

Keywords: Lauraceae, bisbenzylisoquinoline, aporphine, Alseodaphne corneri. 